\title{
Thermal Evaluation of Graphene Nanoplatelets Nanofluid in a Fast-Responding HP with the Potential Use in Solar Systems in Smart Cities
}

\author{
M. M. Sarafraz ${ }^{1}\left(\mathbb{D}\right.$, Iskander Tlili ${ }^{2}$, Zhe Tian ${ }^{3}$, Mohsen Bakouri ${ }^{4}$, Mohammad Reza Safaei ${ }^{5,6, * \mathbb{C}}$ \\ and Marjan Goodarzi ${ }^{7}$ (1) \\ 1 School of Mechanical Engineering, the University of Adelaide, South Australia 5005, Australia; \\ mohammadmohsen.sarafraz@adelaide.edu.au \\ 2 Department of Mechanical and Industrial Engineering, College of Engineering, Majmaah University, \\ Al-Majmaah 11952, Saudi Arabia; 1.tlili@mu.edu.sa \\ 3 School of Engineering, Ocean University of China, Qingdao 266100, China; zhetian_ouc@163.com \\ 4 Department of Medical Equipment Technology, College of Applied Medical Sciences, Majmaah University, \\ Al-Majmaah 11952, Saudi Arabia; m.bakouri@mu.edu.sa \\ 5 Division of Computational Physics, Institute for Computational Science, Ton Duc Tang University, \\ Ho Chi Minh City 758307, Vietnam \\ 6 Faculty of Electrical and Electronics Engineering, Ton Duc Thang University, \\ Ho Chi Minh City 758307, Vietnam \\ 7 Department of Mechanical Engineering, Lamar University, Beaumont, TX 77705, USA; \\ mgoodarzi@lamar.edu \\ * Correspondence: cfd_safaei@tdtu.edu.vn; Tel.: +1-502-657-9981
}

Received: 25 April 2019; Accepted: 16 May 2019; Published: 22 May 2019

\begin{abstract}
An experimental study was undertaken to assess the heat-transfer coefficient (HTC) of graphene nanoplatelets-pentane nanofluid inside a gravity-assisted heat pipe (HP). Influence of various parameters comprising heat flux, mass fraction of the nanoparticles, installation angle and filling ratio (FR) of the working fluid on the HTC of the HP was investigated. Results showed that the HTC of the HP was strongly improved due to the presence of the graphene nanoplatelets. Also, by enhancing the heat flux, the HTC of the HP was improved. Two trade-off behaviors were identified. The first trade-off belonged to the available space in the evaporator and the heat-transfer coefficient of the system. Another trade-off was identified between the installation angle and the residence time of the working fluid inside the condenser unit. The installation angle and the FR of the HP were identified in which the HTC of the HP was the highest. The value of installation angle and filling ratio were $65^{\circ}$ and 0.55 , respectively. Likewise, the highest HTC was obtained at the largest mass fraction of the graphene nanoplatelets which was at wt. $\%=0.3$. The improvement in the HTC of the $\mathrm{HP}$ was ascribed to the Brownian motion and thermophoresis effects of the graphene nanoplatelets.
\end{abstract}

Keywords: graphene; n-pentane; thermosyphon; Thermal performance; tilt angle; filling ratio

\section{Introduction}

With the continuous advancement and development in the structure of the cities, demand for new technologies and, as a result, energy has increased [1]. With limitation in fossil fuel and environmental pollution due to the combustion of carbonaceous fuels, special attention has been paid to renewable energies as a reliable source of energy [2,3]. Solar energy is one of the potential renewable energy resources, which is available to a vast region of the world. However, the intermittent behavior of solar energy during the on-sun and off-sun periods dictates that the solar receivers and collectors 
must have plausible thermal efficiency to maximize the energy absorption from the sun [4-6]. A solar thermal collector is a two-phase apparatus embedded with heat pipes (HPs) to absorb the solar thermal energy and transport it to the top header using the HPs [7]. A HP is a heat-exchanging medium, which employs a working fluid with plausible thermal properties with low boiling point which can easily be evaporated inside the HP [8-11]. A HP composed of an "evaporator section", in which the working fluid is evaporated using boiling mechanism and flows through an "adiabatic section" to reach a "condenser section". In the condenser section, the vapor phase loses its thermal energy and is condensed to the liquid phase. The formed liquid returns to the evaporator using a gravity-assisted falling film. The heat transfer in HPs does not need any external energy, thereby nominating HPs as one of the efficient technologies for heat transfer within a confined space. The current HPs employ alcohols and acetone as the working fluid; however, these working fluids have poor thermal conductivity, which strongly affects the thermal performance of the HPs. Since Aragon National Laboratory introduced the "nanofluids", a new direction of research was developed in thermal engineering science and in different research areas including single and two-phase heat transfer [8,12-19]. A nanofluid is a suspension of some conductive powders such as metal oxides uniformly dispersed within a common cooling fluid such as water or oil [20-22]. Hence, dispersion of nanoparticles requires specific techniques such as using ultrasonic waves and controlling the $\mathrm{pH}$ value of the nanofluid [21].

So far, many endeavors have been made to understand the effect of nanofluids on the thermo-physical properties of nanofluids. Thermal conductivity is one of the key physical properties of the nanofluids, which strongly influences the HTC of the system. Together with thermal conductivity, the heat capacity of the working fluid is another important parameter, which can improve the thermal characteristics of a system. Studies have also shown that the presence of the nanoparticles in the liquid adds some nano-scale phenomena into the heat-transfer mechanism. The first important contributor is the Brownian motion of the nanoparticles that enhances the heat transfer by random walk and random motion of the particles within the system $[23,24]$. In a random movement, particles collide with the hot walls and absorb the thermal energy by conduction mechanism and carry the thermal energy to the cold region and release the thermal energy with the convection heat transfer. The thermophoresis phenomenon is another participant to the heat-transfer increment, in which the nanoparticles move from the hot wall to the cold wall due to the temperature gradient between the cold and hot wall [25].

Considering the above advantages of the nanofluids, many endeavors have been undertaken to use the nanofluids in thermal systems. The usage of the nanofluids in HPs has substantially been reviewed in the literature. For instance, Shafahi et al. [26] numerically studied the HTC of three different nanofluids including $\mathrm{Al}_{2} \mathrm{O}_{3}, \mathrm{TiO}_{2}$, and $\mathrm{CuO}$ nanoparticles flowing through a cylindrical pipe. They modeled the system using a 2D model by assuming a steady state condition as well as incompressible and Newtonian nanofluids. Their outcomes illustrated that by using the nanofluids, thermal resistance of the system is suppressed, and the temperature gradient is reduced due to the promotion of the heat transfer. Also, using nanoparticle with smaller diameter or at higher concentration can potentially reduce the thermal resistance of the system. Naphon et al. [27] perused the influence of $\mathrm{TiO}_{2}$ nanoparticle with average size of $21 \mathrm{~nm}$ on the heat-transfer mechanisms of alcohols in the HPs. They observed that by adding particles at $0.1 \%$ of volume fraction to the alcohol, the heat-transfer coefficient (HTC) can be enhanced by $10.6 \%$. Azari and Derakhshandeh [28] performed some experiments to study the efficacy of aluminum oxide/ $\mathrm{H}_{2} \mathrm{O}$ nanofluid on the HTC of a HP heat exchanger in the presence of butterfly tube inserts when the HP is at constant heat flux. The results illustrated that by adding nanoparticle to the system, a significant enhancement for Nusselt number was gained ( 345\%). Abdollahi-Moghaddam et al. [29] carried out an experiment on $\mathrm{CuO} / \mathrm{H}_{2} \mathrm{O}$ nanofluid flowing through a tube to investigate the energy efficiency of a system working with HP. Also, an ANN model was expanded to investigate the thermal efficiency of the HP. It was identified the efficiency of the system can be improved with nanofluids. It was also understood that the heat transfer can be promoted up to 2.8 times, compared to the base fluid. They demonstrated that using a nanofluid can suppress the consumption of working fluid by $37 \%$ and can diminish the size of the system by $55 \%$. Sarafraz et al. [11] carried a set of experiments 
out, to peruse a $\mathrm{HP}$ working with $\mathrm{ZrO}_{2}$ /acetone nanofluid. The setup was fabricated to simulate a solar collector. As expected, nanofluid diminishes the thermal resistance and gained HTC by $36.3 \%$. Abdul Hamid et al. [6] experimentally analyzed the efficacy of $\mathrm{TiO}_{2}-\mathrm{SiO}_{2} /$ water-EG nanofluid on the HTC of a HP. They found the heat-transfer efficiency can be improved by $254.4 \%$, whereas the friction factor was also augmented by $76 \%$, compared to the base fluid. Sarafraz et al. [11] fulfilled several experiments to study the efficacy of CNT/water nanofluid on HTC of a flat HP. They proved that the HTC of the system was improved by $40 \%$, compared to water. HTC of pulsating HP (PHP) using $0.25-1.5 \mathrm{~g} / \mathrm{lit}$ of $\mathrm{GO} / \mathrm{H}_{2} \mathrm{O}$ nanofluids was experimentally studied by Nazari et al. [30]. Their results demonstrated that the thermal resistance of a HP can be diminished by $42 \%$, while thermal conductivity and viscosity both increased when nanofluid was employed in the HP. Togun et al. [31] modeled a HP including a double forward-facing steps where $\mathrm{CuO} /$ water and $\mathrm{Al}_{2} \mathrm{O}_{3} /$ water were employed inside the HP. The results showed that Nusselt number can be augmented by raising the nanofluid's concentration, height of the step, and the fluid velocity. Also, they found that alumina/water nanofluid at vol. $\%=4$ has the highest HTC.

Facing with the above literature, it can be stated that despite immense accomplished studies on the potential usage of the nanofluids in various thermal systems, less studies have been devoted to the solar thermal energy with the focus on the application of the nanofluids in smart cities, in which energy plays a key role in the municipal development. Renewable energy can open a new door towards the sustainability of the smart cities and nanofluid can contribute to this. Hence, in this study, a fundamental research is fulfilled to assess the feasible application of graphene nanoplatelets-n-pentane as the working fluid inside the HPs. N-pentane with the very high vapor pressure can be a fast-responding working fluid in the HP. Also, the presence of the graphene can improve the thermal characteristics of n-pentane. Accordingly, a thermosyphon HP is employed and effect of several operating parameters such as the applied thermal energy to the evaporator, the installation tilt angle, the filling ratio (FR) of the working fluid and the mass fraction of the nanofluid on the HTC of the evaporator and the efficiency of the HP is experimentally studied. The developed nanofluid can take advantage of good thermal properties of n-pentane while also improving the efficiency of the system due to the presence of the graphene nanoplatelets. N-pentane has reasonably good thermal features and has higher vapor pressure than alcohols and acetone. Therefore, it can easily evaporate and absorb large amount of heat due to the latent heat. However, the thermal conductivity of n-pentane is weak; thereby adding graphene can plausibly increase the thermal conductivity of the working fluid. For solar applications, high heat removal capability is a key characteristic which needs a working fluid with quick response. Due to the large vapor pressure and plausible thermal performance, $n$-pentane/graphene was selected for the present study.

\section{Experimental}

\subsection{Test Rig}

Figure 1 displays a schematic of the used apparatus for assessing the HTC of the HP. The test rig comprised of a charging loop, which was used to charge the working fluid into the HP. The charging loop included a vacuum pump, a syringe pump, and the circulation pipes. The volume of the working fluid charged into the system was accurately measured with the syringe pump. Using the charging loop, the value of the HTC was determined. Notably, during the charging process, the HP was de-aerated with the vacuum pump at $10 \mathrm{kPa}$. The heart of the system was a gravity-assisted thermosyphon with an evaporator with rough walls, adiabatic section in the middle and a condenser part connected to a refrigerant cooling system. The evaporator part was heated up with an flexi cartridge with power throughput of 1400 Watt. Three thermocouples were installed on the evaporator section, two on the adiabatic, and three on the condenser to record the temperature change along with the length of the HP. Also, the HP was heavily insulated to minimize the heat loss to the environment. Notably, the HP was purchased from RS-components Company and the working fluid was only replaced with the nanofluids. 
All the thermocouples were connected to a data logger with frequency of $1 \mathrm{kHz}$ connected to a PC. The installation angle (referred to as tilt angle) of the HP was changed with a base equipped with an inclinator to accurately measure the angle of the HP with the horizon line. The experiments were conducted for various installation angles, HTCs, heat fluxes and mass fraction of the nanoparticles and the temperature distribution profile and HTC of the evaporator were measured. The internal pressure of the HP was constantly monitored to ensure that it was not pressured during the charging process.

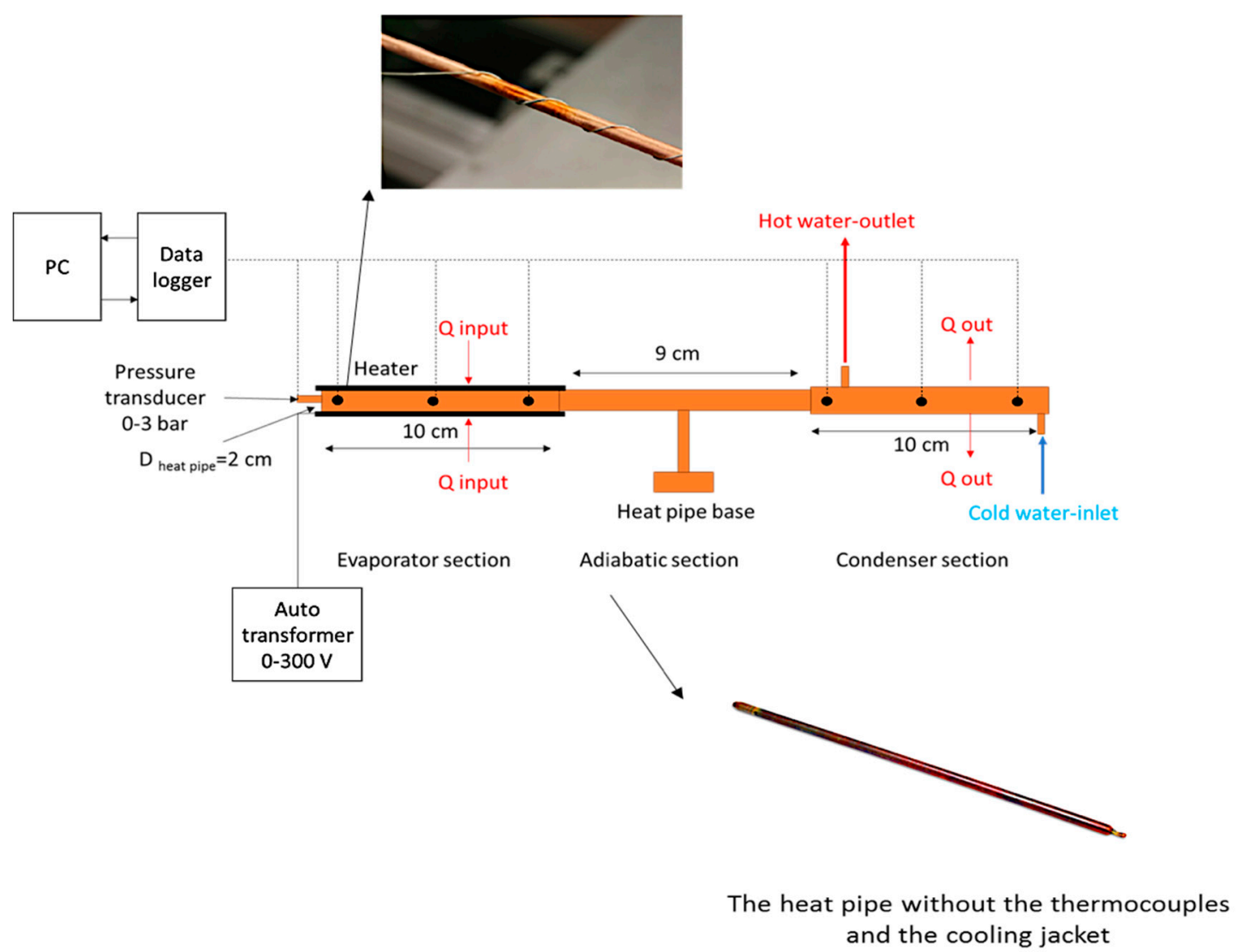

Figure 1. A schematic illustration of the studied apparatus.

\subsection{Preparation of the Working Fluid}

To prepare the nanofluids, graphene nanoplatelets were purchased from USNANO Company and were dispersed in n-pentane purchased from Sigma. Following method was followed to obtain the nano-suspension of graphene-n-pentane nanofluid (GNP-pentane):

(1) Initially, the graphene nanoplatelets were weighted with a balancer. For $1 \mathrm{~kg}$ of n-pentane, the desired mass of graphene platelets was dispersed in n-pentane such that the nanofluids were prepared at weight percentages of $0.1,0.2$ and 0.3 .

(2) A magnetic stirrer was used to uniformly disperse the GNPs into n-pentane at stirring speed of $300 \mathrm{rpm}$ for 10 minutes. However, due to the potential agglomeration of the nanoparticles, an ultrasonic homogenizer was employed at 350 Watt and frequency of $40 \mathrm{kHz}$ for almost 10 minutes to crack the clusters and agglomerated particles.

(3) To increase the stability of the nanoparticles, an anionic surfactant of nonyl phenol ethoxylate was added to the nano-suspensions and the nano-suspensions were stirred for 5 more minutes to uniformly disperse the surfactant inside the nano-suspension.

(4) $\mathrm{pH}$ of the nano-suspensions was also regulated with a buffer solution to minimize the fouling formation within the system. A mixture of $\mathrm{HCl}$ and $\mathrm{NaOH}$ at $0.1 \mathrm{mM}$ was employed. 
(5) Time-settlement experiments were employed to ensure about the stability of the nanofluids. To perform, nanofluids were placed inside the containers at various $\mathrm{pH}$ values and the sedimentation of the nanoparticles was constantly monitored to identify the best conditions in which the thickness of the sedimentation layer is minimized. Stability tests results illustrated that nanofluid could be stable for three weeks, which was sufficient for conducting the experiments.

\subsection{Data Reduction}

To measure the thermal resistance of the evaporator part, can be represented by:

$$
R=\frac{T_{e}-T_{a}}{Q}
$$

Here, $Q$ is the applied heat to the evaporator section, $T_{e}$ and $T_{a}$ are the evaporator's and adiabatic temperatures. Also, the HTC of the evaporator section was calculated with the following equation:

$$
h=\frac{q^{\prime \prime}}{T_{e}-T_{a}}=\frac{V \times I}{T_{e}-T_{a}}
$$

Here, $V$ and $I$ are the voltage and current applied to the AC flexi cartridge, which according to Joule's effect can control the applied heat to the evaporator section.

The FR of the HP is defined as follows:

$$
F R=\frac{v_{n f}}{v_{\text {evap }}}
$$

Here, $v_{n f}$ is the volume of the working fluid in the evaporator $\left(\mathrm{cm}^{3}\right)$ and $v_{\text {evan. }}$ is the total volume of the evaporator $\left(\mathrm{cm}^{3}\right)$. The amount of FR was controlled with the syringe pump flow meter. Tilt angle is also defined as the angle between the body of the hat pipe and the horizon line and it was measured using inclinometer. To assess the uncertainty of the tests, the equation presented by Kline-McClintock [32] was used and the uncertainty of $4.5 \%$ and $5.1 \%$ were obtained for the heat-transfer coefficient and thermal resistance, respectively considering the accuracy of $1 \%$ for thermocouples, $1 \%$ for voltage and current.

To evaluate the uncertainty analysis, Kline-McClintock technique was employed [33]. Considering the accuracy of the instruments ( $1 \%$ of reading value for thermocouple, $0.1 \%$ for voltage and current, $1 \%$ for inclination meter and $0.1 \%$ for the syringe pump), the uncertainty value for the heat-transfer coefficient of the evaporator was $\pm 6.9 \%$.

\section{Results and Discussion}

\subsection{Temperature Profile}

Figure 2 displays the temperature distribution along the length of the HP for pure pentane and GNP-n-pentane nanofluid at $\mathrm{q}^{\prime \prime}=5 \mathrm{~kW} / \mathrm{m}^{2}$. As shown, the temperature in the evaporator is high, while gradually reduces in the adiabatic and reaches the lowest at the condenser. For pentane, the temperature of the evaporator is relatively close to the boiling temperature of pentane, hence, there is a potential for incipience of the boiling heat transfer in the evaporator section. If boiling hat transfer occurs in the evaporator, due to the formation of the bubbles, the HTC considerably increases, which can be attributed to the bubble interactions and the local agitation due to the bubble movements close to the walls of the evaporator. Interestingly, for GNP-pentane nanofluid, it can be seen that along the length of the HP, temperature decreases compared to pure n-pentane. This is because; more heat is absorbed by the working fluid due to the increase in the conduction heat transfer and thermal conductivity of the working fluid. For example, in the evaporator region, the average temperature of $\mathrm{HP}$ for pentane was $78^{\circ} \mathrm{C}$, while for nanofluids at wt. $\%=0.1,0.2$ and 0.3 , it was $75^{\circ} \mathrm{C}, 72{ }^{\circ} \mathrm{C}$ and $69.5^{\circ} \mathrm{C}$, respectively. 
This is because; the GNPs absorb the thermal energy using conduction mechanism and transfer it to the cold region of the working fluid using conduction-conduction and conduction-convection mechanisms. Hence, the heat-transfer mechanism is improved in the evaporator, which in turn improves the total HTC of the HP.

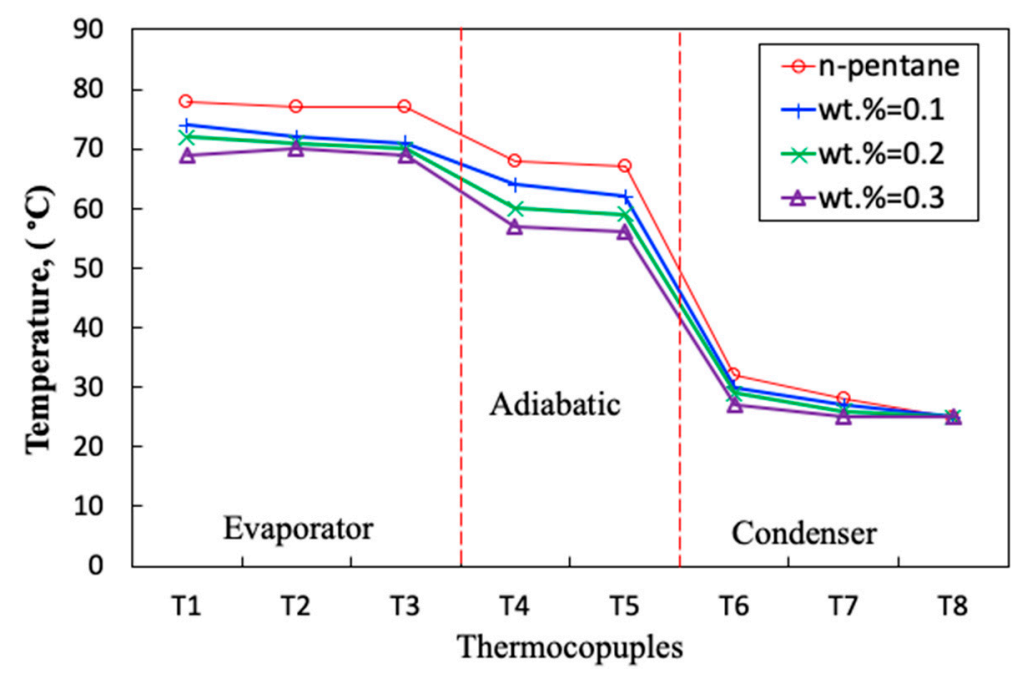

Figure 2. The temperature distribution of the HP for pentane and GNP-pentane nanofluids.

As can also be seen in Figure 3, the thermal resistance of the HP decreases by increasing the applied heat flux to the evaporator section. This can be ascribed to the increment in the HTC of the HP, which is an intensified at large heat flux value. Also, the thermal resistance showed an asymptotic behavior meaning that at high heat flux conditions, the thermal resistance of the HP is minimized. With adding more nanomaterials to the working fluids, the thermal resistance of the HP is more suppressed. Furthermore, the thermal resistance of the HP at heat fluxes $>25 \mathrm{~kW} / \mathrm{m}^{2}$ is almost constant showing the stability of the working fluid inside the studied system.

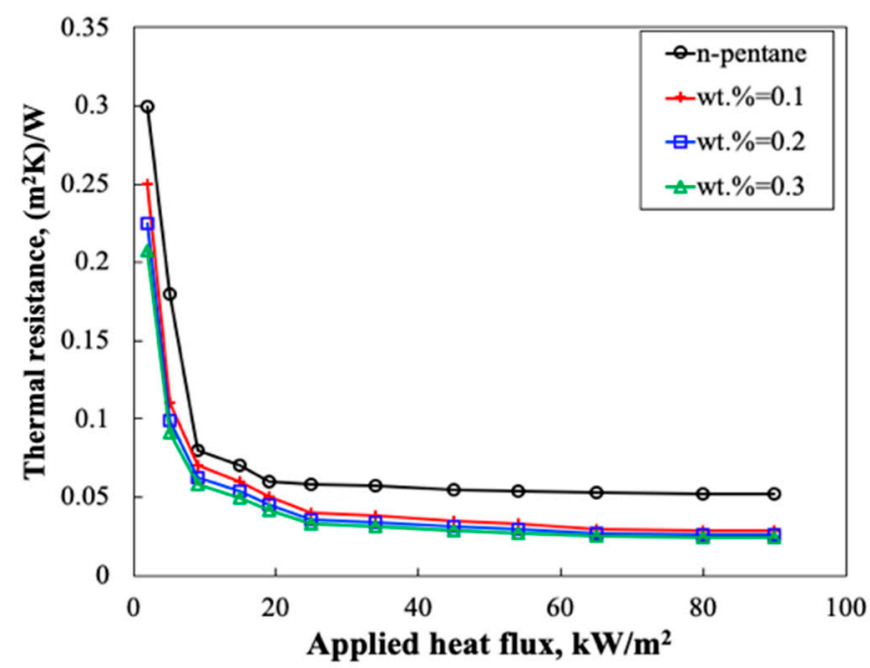

Figure 3. Variation of the thermal resistance with the applied heat flux for n-pentane and nanofluids.

The thermal resistance strongly depends on the temperature difference between the adiabatic and the evaporator section. Initially, for small applied heat, the convective heat transfer is the dominant mechanism of heat transfer, hence, with an increase in the applied heat, the temperature of the working fluid increases reaching the boiling point of the working fluid. Then, with an increase in the applied, only the bubble formation can potentially increase, and temperature of the working fluid remains 
constant. Hence, for high applied heat to the evaporator, the thermal resistance or thermal performance off the HP remains unchanged.

\subsection{Effect of Heat Flux}

Figure 4 presents the alteration of the HTC of the evaporator with the applied heat flux to the evaporator. As can be seen, with increasing the applied heat flux to the evaporator region, the HTC of the heat pipe increases, which can be attributed to the intensification of the heat-transfer mechanism from convective heat transfer towards the nucleate boiling. Also, at higher heat fluxes, the rate of the evaporation increases as well. Notably, the slope of increase from a specific heat flux changes and is promoted. For example, for heat fluxes $<25 \mathrm{~kW} / \mathrm{m}^{2}$, the HTC increases slightly with heat flux; however, for heat fluxes $>25 \mathrm{~kW} / \mathrm{m}^{2}$ the HTC increases significantly, which can be attributed to the incipience of the nucleate boiling in the evaporator, which promotes the HTC of the system. As an example, at heat flux (HF) of $20 \mathrm{~kW} / \mathrm{m}^{2}$, the HTC for pentane was $1755 \mathrm{~W} /\left(\mathrm{m}^{2} \mathrm{~K}\right)$, though, at $\mathrm{HF}=45 \mathrm{~kW} / \mathrm{m}^{2}$, the HTC was $2900 \mathrm{~W} /\left(\mathrm{m}^{2} \mathrm{~K}\right)$. Also, for the nanofluids, the HTC was larger than those of measured for pentane. For instance, for wt. $\%=0.1$, at $\mathrm{HF}=90 \mathrm{~kW} / \mathrm{m}^{2}$, the HTC was $7900 \mathrm{~W} / \mathrm{m}^{2} . \mathrm{K}$, whereas it was $8210 \mathrm{~W} / \mathrm{m}^{2}$. K and $9820 \mathrm{~W} / \mathrm{m}^{2}$. K for wt. $\%=0.2$ and 0.3 , respectively.

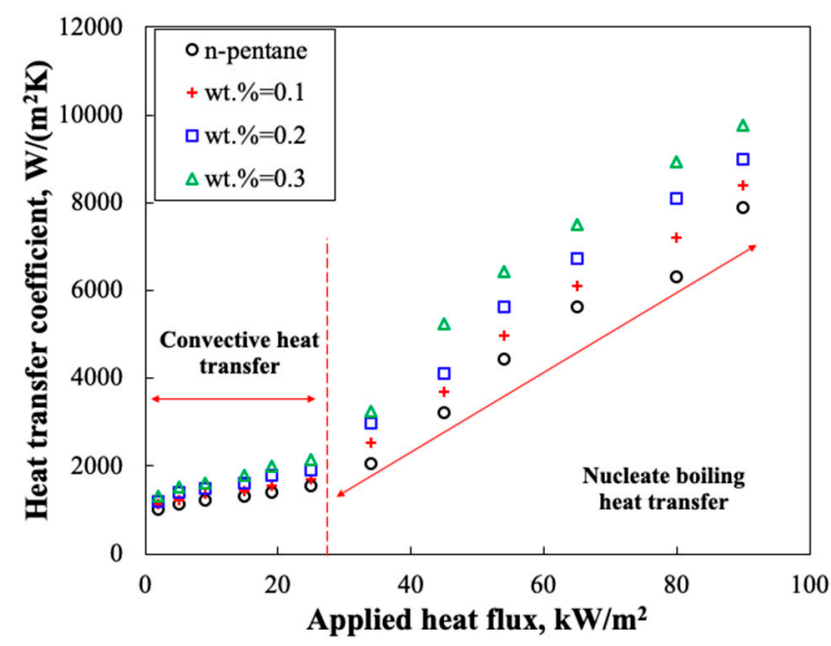

Figure 4. Alteration of the HTC with heat flux for n-pentane and nanofluids.

Figure 5 also shows the enhancement in the HTC of the evaporator. As can be seen, the enhancement in the HTC for region in which HF is $<25 \mathrm{~kW} / \mathrm{m}^{2}$ is relatively small in comparison with those of recorded for the HF $>25 \mathrm{~kW} / \mathrm{m}^{2}$. For example, for wt. $\%=0.1$, the HTC enhancement at HF of $15 \mathrm{~kW} / \mathrm{m}^{2}$, and $25 \mathrm{~kW} / \mathrm{m}^{2}$ was 1.08 and 1.12, respectively. However, at $\mathrm{HF}$ of $35 \mathrm{~kW} / \mathrm{m}^{2}$ and $80 \mathrm{~kW} / \mathrm{m}^{2}$, it was 1.24 and 1.13. As discussed, this can be attributed to the incipience of the nucleate boiling heat transfer, which further promotes the HTC of the system. Also, owing to the presence of the GNPs, the Brownian motion and the thermophoresis effect of the GNPs, improves the HTC of the system. Hence, nanofluid showed better HTC in comparison with pure pentane. 


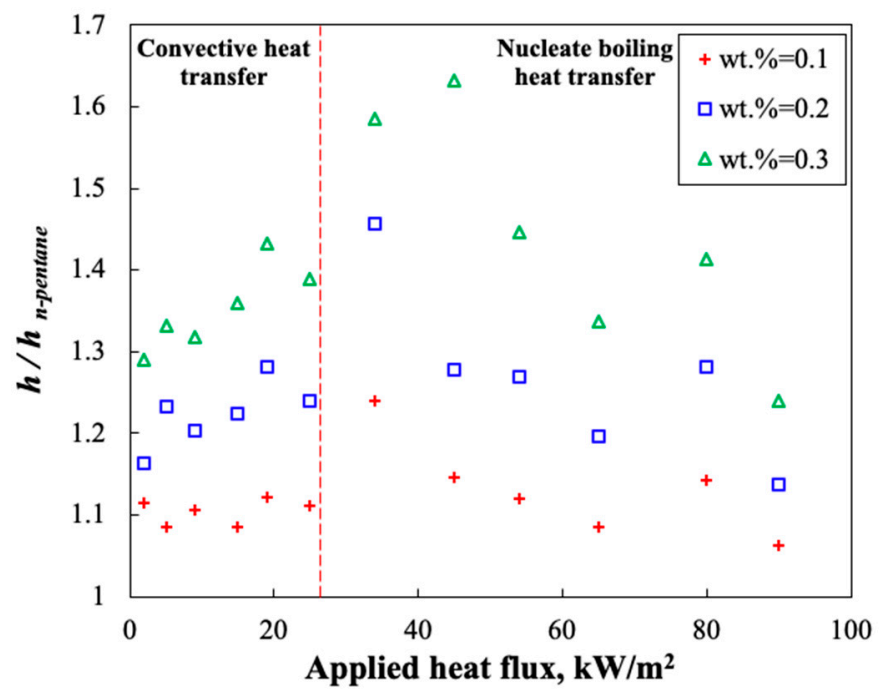

Figure 5. Variation of $h_{\text {nanofluid }} / h_{n-p e n t a n e}$ with the applied heat flux for various mass fractions of graphene nanoplatelets in n-pentane.

\subsection{Filling Ratio}

Figure 6 shows the variation of the HTC of the system with the HTC for heat flux of $65 \mathrm{~kW} / \mathrm{m}^{2}$ for pure pentane and nanofluids. In this heat flux, nucleate boiling occurs as temperature of the evaporator was above $100^{\circ} \mathrm{C}$. As is clear, initially, with increasing the HTC of the HP, the HTC of the system increases reaching to a point that a trade-off occurs between the space available in the evaporator for the migration of vapor to the condenser and the amount of the liquid available in the evaporator. On the other hand, with a raise in the amount of the working fluid, the thermal capacity of the fluid augments. It should be noted that the space available in the HP becomes a limiting factor. Therefore, there is an optimum for the HTC, which is 0.55 for the present work. For example, at FR = 0.55 the HTC for water and nanofluids at $0.1 \%, 0.2 \%$ and $0.3 \%$ are maximized which are $5200 \mathrm{~W} /\left(\mathrm{m}^{2} \mathrm{~K}\right)$, $5450 \mathrm{~W} /\left(\mathrm{m}^{2} \mathrm{~K}\right), 5510 \mathrm{~W} /\left(\mathrm{m}^{2} \mathrm{~K}\right)$ and $5700 \mathrm{~W} /\left(\mathrm{m}^{2} \mathrm{~K}\right)$, respectively.

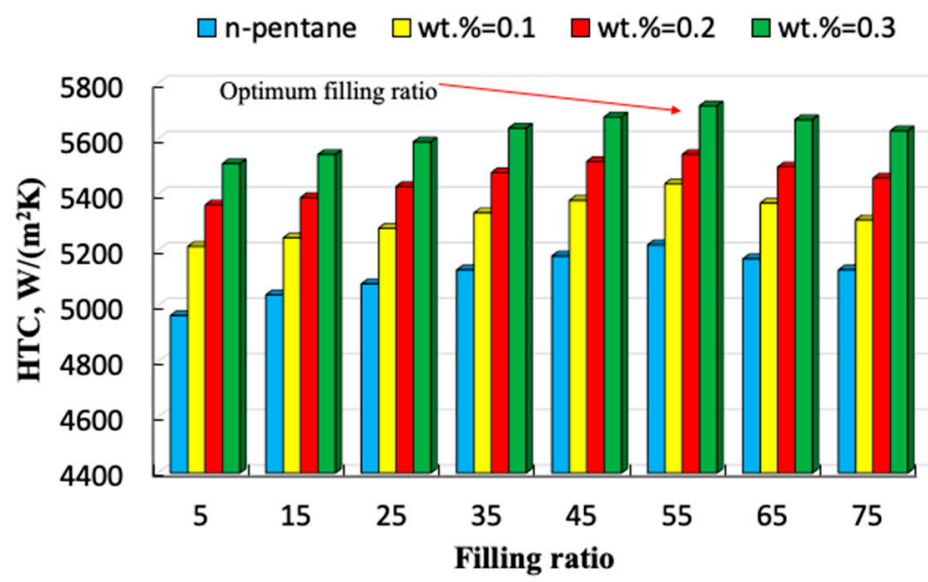

Figure 6. Variation of the HTC of the system with the HTC value for pure n-pentane and nanofluids.

\subsection{Installation Angle}

Figure 7 demonstrates the dependence of the HTC of the system on the installation angle (IA) of the HP for pure n-pentane and nanofluids. As can be seen, there is another trade-off identified for the HP such that with increasing the installation angle, the HTC of the system initially intensifies reaching to a point in which the HTC starts to diminish with increasing the installation angle. For example, at IA $=5$, the HTC for n-pentane and nanofluid at wt. $\%=0.3$ was $4500 \mathrm{~W} /\left(\mathrm{m}^{2} \mathrm{~K}\right)$ and $4900 \mathrm{~W} /\left(\mathrm{m}^{2} \mathrm{~K}\right)$, respectively. 
However, by increasing the IA to $65^{\circ}$, the HTC of the system improved to 4800 and $5300 \mathrm{~W} /\left(\mathrm{m}^{2} \mathrm{~K}\right)$, respectively and decreased to $4600 \mathrm{~W} /\left(\mathrm{m}^{2} \mathrm{~K}\right)$ and $5085 \mathrm{~W} /\left(\mathrm{m}^{2} \mathrm{~K}\right)$ for IA $=75^{\circ}$. This can be attributed to the effect of gravity forces on the liquid working fluid. For small angles, the effect of gravity is insignificant; hence return of the working fluid to the evaporator is not strongly affected by the gravity. However, for larger angles, such return is facilitated due to the gravity. However, this adds another trade-off to the system. By facilitating the return of the working fluid to the evaporator, the residence time inside the condenser considerably decreases and working fluid does not have sufficient time to transfer the heat to the surrounding. Hence, at installation angle of $65^{\circ}$, the largest HTC was recorded for the system. This angle was the same for nanofluids and for the n-pentane as well.

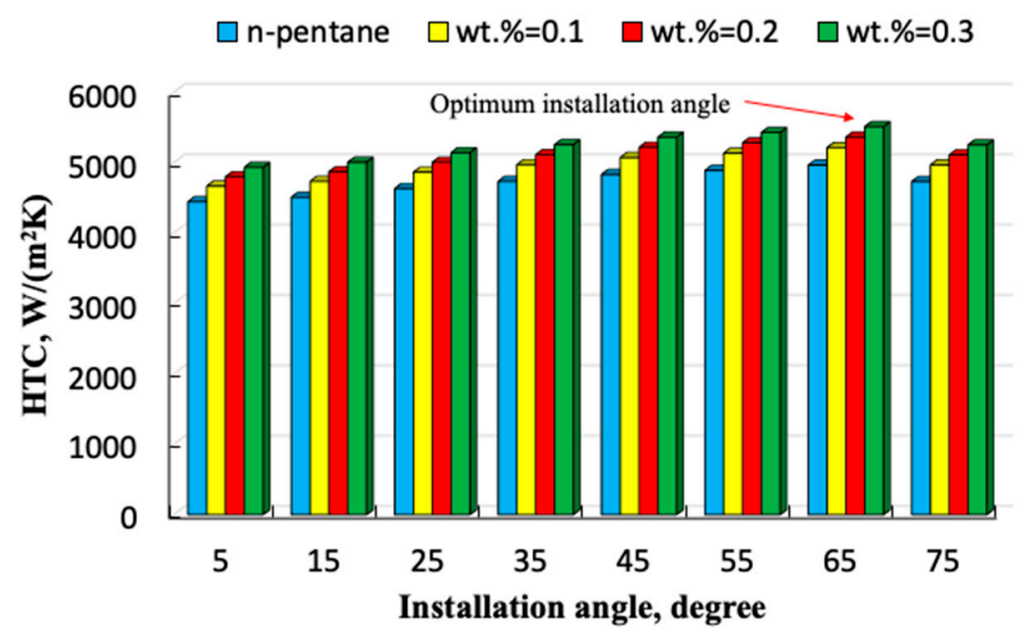

Figure 7. Variation of the HTC with the installation angle of the HP for pure n-pentane and nanofluids.

It is worth saying that there are several operating parameters which can potentially limit the heat-transfer rate and operation of the HP. These parameters include rate of the boiling heat transfer, the capillary effect, vapor velocity (sonic limitation) and entrainment of the liquid and vapor phases. Depending on the structure of the thermosyphon and heat pipe, any of above parameters can affect the thermal performance of the system. If the rate of the boiling heat transfer is relatively large, the dry-out phenomenon and critical heat flux occur, which can damage the evaporator section of the heat pipe. Also, if the rate of the evaporation is large, the gas velocity can reach to the sonic level (if diameter is very small, which causes a limitation in the heat transfer. Also, if the amount of vapor is high, it can causes a choked flow or even entrainment in the adiabatic or evaporator sections [34,35].

\section{Conclusions}

In this investigation, results of an experimental investigation on the HTC of a HP working with graphene nanoplatelets-n-pentane nanofluid were reported. It was identified that the presence of graphene nanoplatelets promoted the HTC of the HP. It was also found that by boosting the applied heat flux to the evaporator, the HTC of the system augmented. This was ascribed to the incipience of the nucleate boiling heat transfer of the evaporator. However, HTC and installation angle represented trade-off behavior in the system. The former showed trade-off behavior between the space available in the evaporator and the amount of the liquid working fluid; however, the latter revealed a trade-off between the effect of the gravity force on the liquid working fluid and the residence time of the working fluid inside the condenser. Overall, the presence of the graphene nanoplatelets promoted the Brownian motion and thermophoresis effect, which in turn improved the HTC of the system.

Author Contributions: Conceptualization, M.R.S and M.M.S.; methodology, All authors equally contributed to this; formal analysis, All authors equally contributed to this; writing—original draft preparation, M.M.S., M.G. and M.R.S; writing - review and editing, All authors equally contributed to this. 
Funding: The authors extend their appreciation to the Deanship of Scientific Research at Majmaah University for supporting this work under project number No. (RGP-2019-17). Zhe Tian wants to acknowledge the following grants: NSFC (51709244), Taishan Scholar (tsqn201812025) and Fundamental Research for Central Universities (201941008).

Acknowledgments: The first and fifth authors of this work tend to appreciate Rayan Sanat Co. for their financial supports and sharing the HP facility.

Conflicts of Interest: The authors declare no conflict of interest.

\section{References}

1. Tsai, C.; Chien, H.; Ding, P.; Chan, B.; Luh, T.-Y.; Chen, P.-H. Effect of structural character of gold nanoparticles in nanofluid on heat pipe thermal performance. Mater. Lett. 2004, 58, 1461-1465. [CrossRef]

2. Panwar, N.; Kaushik, S.; Kothari, S.; Panwar, D.N.L. Role of renewable energy sources in environmental protection: A review. Renew. Sustain. Energy Rev. 2011, 15, 1513-1524. [CrossRef]

3. Dincer, I. Renewable energy and sustainable development: A crucial review. Renew. Sustain. Energy Rev. 2000, 4, 157-175. [CrossRef]

4. Kreith, F.; Kreider, J.F. Principles of Solar Engineering; Hemisphere Publishing Corp.: Washington, DC, USA, 1978; p. 790.

5. Tian, Y.; Zhao, C. A review of solar collectors and thermal energy storage in solar thermal applications. Appl. Energy 2013, 104, 538-553. [CrossRef]

6. Olia, H.; Torabi, M.; Bahiraei, M.; Ahmadi, M.H.; Goodarzi, M.; Safaei, M.R. Application of Nanofluids in Thermal Performance Enhancement of Parabolic Trough Solar Collector: State-of-the-Art. Appl. Sci. 2019, 9, 463. [CrossRef]

7. Kreider, J.F.; Kreith, F. Solar Energy Handbook; McGraw-Hill: New York, NY, USA, 1981.

8. Arya, A.; Sarafraz, M.M.; Shahmiri, S.; Madani, S.A.H.; Nikkhah, V.; Nakhjavani, S.M. Thermal performance analysis of a flat heat pipe working with carbon nanotube-water nanofluid for cooling of a high heat flux heater. Heat Mass Transf. 2018, 54, 985-997. [CrossRef]

9. Sarafraz, M.; Hormozi, F.; Peyghambarzadeh, S. Thermal performance and efficiency of a thermosyphon heat pipe working with a biologically ecofriendly nanofluid. Int. Commun. Heat Mass Transf. 2014, 57, $297-303$. [CrossRef]

10. Sarafraz, M.; Hormozi, F. Experimental study on the thermal performance and efficiency of a copper made thermosyphon heat pipe charged with alumina-Glycol based nanofluids. Powder Technol. 2014, 266, 378-387. [CrossRef]

11. Sarafraz, M.; Pourmehran, O.; Yang, B.; Arjomandi, M. Assessment of the thermal performance of a thermosyphon heat pipe using zirconia-acetone nanofluids. Renew. Energy 2019, 136, 884-895. [CrossRef]

12. Nakhjavani, M.; Nikkhah, V.; Sarafraz, M.; Shoja, S.; Sarafraz, M. Green synthesis of silver nanoparticles using green tea leaves: Experimental study on the morphological, rheological and antibacterial behaviour. Heat Mass Transf. 2017, 53, 3201-3209. [CrossRef]

13. Nikkhah, V.; Sarafraz, M.; Hormozi, F. Application of spherical copper oxide (II) water nano-fluid as a potential coolant in a boiling annular heat exchanger. Chem. Biochem. Eng. Q. 2015, 29, 405-415. [CrossRef]

14. Sarafraz, M.; Hormozi, F.; Peyghambarzadeh, S.; Vaeli, N. Upward Flow Boiling to DI-Water and Cuo Nanofluids Inside the Concentric Annuli. J. Appl. Fluid Mech. 2015, 8, 651-659.

15. Sarafraz, M.; Hormozi, F.; Silakhori, M.; Peyghambarzadeh, S.M. On the fouling formation of functionalized and non-functionalized carbon nanotube nano-fluids under pool boiling condition. Appl. Therm. Eng. 2016, 95, 433-444. [CrossRef]

16. Sarafraz, M.; Nikkhah, V.; Madani, S.; Jafarian, M.; Hormozi, F. Low-frequency vibration for fouling mitigation and intensification of thermal performance of a plate heat exchanger working with $\mathrm{CuO} /$ water nanofluid. Appl. Therm. Eng. 2017, 121, 388-399. [CrossRef]

17. Sarafraz, M.; Nikkhah, V.; Nakhjavani, M.; Arya, A. Thermal performance of a heat sink microchannel working with biologically produced silver-water nanofluid: Experimental assessment. Exp. Therm. Fluid Sci. 2018, 91, 509-519. [CrossRef] 
18. Sarafraz, M.M.; Peyghambarzadeh, S.; Fazel, S.A.; Vaeli, N. Nucleate pool boiling heat transfer of binary nano mixtures under atmospheric pressure around a smooth horizontal cylinder. Period. Polytech. Chem. Eng. 2013, 57, 71-77. [CrossRef]

19. Sarafraz, M.; Peyghambarzadeh, S.M. Nucleate pool boiling heat transfer to $\mathrm{Al}_{2} \mathrm{O}_{3}$-water and $\mathrm{TiO}_{2}$-water nanofluids on horizontal smooth tubes with dissimilar homogeneous materials. Chem. Biochem. Eng. Q. 2012, 26, 199-206.

20. Yu, W.; France, D.M.; Routbort, J.L.; Choi, S.U.S. Review and comparison of nanofluid thermal conductivity and heat transfer enhancements. Heat Transf. Eng. 2008, 29, 432-460. [CrossRef]

21. Li, Y.; Zhou, J.; Tung, S.; Schneider, E.; Xi, S. A review on development of nanofluid preparation and characterization. Powder Technol. 2009, 196, 89-101. [CrossRef]

22. Kleinstreuer, C.; Feng, Y. Experimental and theoretical studies of nanofluid thermal conductivity enhancement: A review. Nanoscale Res. Lett. 2011, 6, 229. [CrossRef]

23. Jang, S.P.; Choi, S.U.S. Role of Brownian motion in the enhanced thermal conductivity of nanofluids. Appl. Phys. Lett. 2004, 84, 4316-4318. [CrossRef]

24. Prasher, R.; Bhattacharya, P.; Phelan, P.E. Brownian-motion-based convective-conductive model for the effective thermal conductivity of nanofluids. J. Heat Transf. 2006, 128, 588-595. [CrossRef]

25. Malvandi, A.; Ganji, D.D. Brownian motion and thermophoresis effects on slip flow of alumina/water nanofluid inside a circular microchannel in the presence of a magnetic field. Int. J. Therm. Sci. 2014, 84, 196-206. [CrossRef]

26. Shafahi, M.; Bianco, V.; Vafai, K.; Manca, O. Thermal performance of flat-shaped heat pipes using nanofluids. Int. J. Heat Mass Transf. 2010, 53, 1438-1445. [CrossRef]

27. Naphon, P.; Khonseur, O. Study on the convective heat transfer and pressure drop in the micro-channel heat sink. Int. Commun. Heat Mass Transf. 2009, 36, 39-44. [CrossRef]

28. Azari, A.; Derakhshandeh, M. An experimental comparison of convective heat transfer and friction factor of $\mathrm{Al}_{2} \mathrm{O}_{3}$ nanofluids in a tube with and without butterfly tube inserts. J. Taiwan Inst. Chem. Eng. 2015, 52, 31-39. [CrossRef]

29. Abdollahi-Moghaddam, M.; Motahari, K.; Rezaei, A.; Abdollahi-Moghaddam, M.; Motahari, K.; Rezaei, A. Performance characteristics of low concentrations of $\mathrm{CuO} /$ water nanofluids flowing through horizontal tube for energy efficiency purposes; an experimental study and ANN modeling. J. Mol. Liq. 2018, 271, 342-352. [CrossRef]

30. Nazari, M.A.; Ghasempour, R.; Ahmadi, M.H.; Heydarian, G.; Shafii, M.B. Experimental investigation of graphene oxide nanofluid on heat transfer enhancement of pulsating heat pipe. Int. Commun. Heat Mass Transf. 2018, 91, 90-94. [CrossRef]

31. Togun, H.; Ahmadi, G.; Abdulrazzaq, T.; Shkarah, A.J.; Kazi, S.N.; Badarudin, A.; Safaei, M.R. Thermal performance of nanofluid in ducts with double forward-facing steps. J. Taiwan Inst. Chem. Eng. 2015, 47, 28-42. [CrossRef]

32. Kline, S.J.; McClintock, F.A. Describing Uncertainties in Single-Sample Experiments. Mech. Eng. 1953, 75, 3-8.

33. Kline, S. The purposes of uncertainty analysis. J. Fluids Eng. 1985, 107, 153-160. [CrossRef]

34. Faghri, A. Heat pipes: Review, opportunities and challenges. Front. Heat Pipes 2014, 5. [CrossRef]

35. Naphon, P.; Thongkum, D.; Assadamongkol, P. Heat pipe efficiency enhancement with refrigerant-Nanoparticles mixtures. Energy Convers. Manag. 2009, 50, 772-776. [CrossRef]

(C) 2019 by the authors. Licensee MDPI, Basel, Switzerland. This article is an open access article distributed under the terms and conditions of the Creative Commons Attribution (CC BY) license (http://creativecommons.org/licenses/by/4.0/). 